\title{
SIZE, SHAPE, AND SOLUBILITY OF A CLASS OF RELEASABLE CELL SURFACE PROTEINS OF SYMPATHETIC NEURONS ${ }^{1}$
}

\author{
KATHLEEN J. SWEADNER \\ Neurosurgical Research, Massachusetts General Hospital, and Department of Physiology, Harvard Medical School, Boston, \\ Massachusetts 02114
}

Received February 24, 1983; Revised May 23, 1983; Accepted June 29, 1983

\begin{abstract}
Exposed on the cell surface of sympathetic neurons in culture is a family of high molecular weight glycoproteins (B1, B2, B3, and B4, related to the NILE protein) which undergoes post-translational modification (Sweadner, K. J. (1983) J. Neurosci. 3: 2504-2517). B1 and B3 are converted to B2 and $\mathrm{B} 4$ by what might be limited proteolysis. These proteins normally require detergents to release them from the cells. When neurotransmitter release is evoked chemically, however, derivatives of the proteins (S2 and $\mathrm{S} 4$ ) are released into the medium. A hydrodynamic analysis of the structure of the released proteins and their membrane-associated precursors was undertaken to determine whether the proteins are released as membrane fragments, aggregates, or monomers in solution, and to give information on the structure and disposition of the proteins on the cell surface.

Measurements of the Stokes radii, sedimentation coefficients, partial specific volumes, and frictional coefficients of the proteins indicate that they are released into the medium as soluble monomers. The hydrodynamic analysis also indicates that they are nonglobular (probably fibrous) in shape, both before and after post-translational modification and release. Their true molecular weights are calculated to be $\sim 130,000$ to 170,000 . Although B1, B2, B3, and B4 are probably intrinsic membrane proteins, their releasability suggests that most of their mass is exposed to the aqueous extracellular medium.
\end{abstract}

Previous work has demonstrated the existence of a group of four high molecular weight, acidic glycoproteins on the surface of cultured sympathetic neurons of the rat, by analysis of two-dimensional gels (Braun et al., 1981). These proteins, like many of the other surface proteins, contain sialic acid, fucose, and galactose or galactosamine, and they can be labeled by lactoperoxidase-catalyzed iodination of intact cells. A similar group of high molecular weight and acidic proteins was found to be released into the culture medium when cultures were treated with black widow spider venom to evoke neurotransmitter release (Sweadner, 1981). The accompanying paper provides evidence that the released proteins (S2 and S4) are derived not from synaptic vesicles, but from the cell surface glycoproteins (B1, B2, B3, and $\mathrm{B} 4$ ), and that the proteins undergo a series of modifications before they are released (Sweadner, 1983). Proteins

\footnotetext{
${ }^{1}$ I would like to thank Paul H. Patterson, Eva J. Neer, and Stanley M. Goldin for their invaluable criticisms and encouragement, and R. C. Gilkeson for skillful technical assistance. This work was supported by a grant from the Milton Fund, Harvard University. K. J. S. is an Established Investigator of the American Heart Association and a Fellow of the Sloan Foundation.
}

$\mathrm{B} 1, \mathrm{~B} 2$, and $\mathrm{S} 2$ are antigenically related to the NILE (nerve growth factor-inducible, large external) protein of pheochromocytoma PC12 cells (McGuire et al., 1978; Lee et al., 1981; Salton et al., 1983).

The release or shedding of cell surface proteins has been described in many cells in culture and has been variously proposed to be due to the pinching off of membrane fragments, the abandonment of substrateattached proteins during active cell movement, and the release or secretion of particles (adherons) associated with extracellular matrix components (Schubert and LaCorbiere, 1982). The most direct way to determine the mechanism by which the sympathetic neuron surface proteins are released would be to determine the molecular size of the proteins before and after release.

Within certain theoretical limitations, it is possible to obtain information about the size and shape of a protein from its behavior on gel filtration columns and its sedimentation in sucrose density gradients. Three molecular parameters can be measured: Stokes radius, sedimentation coefficient, and partial specific volume. From these, a molecular weight can be calculated to determine whether the particles in solution are monomers or aggregates of larger size, and the frictional ratio, $f / f_{o}$, can be 
calculated to estimate whether the shape of the protein deviates from that of a compact sphere. These hydrodynamic parameters were measured for B1, B2, B3, and B4 dissolved in the non-ionic detergent NP-40 (Nonidet P40 ), and for $\mathrm{S} 2$ and $\mathrm{S} 4$ in the absence of detergent. The data were used to calculate the physical size and shape of the proteins before and after their release.

\section{Materials and Methods}

Methods for the culture of sympathetic neurons, for the iodination of their cell surface proteins, for the metabolic labeling of their proteins with $\left[{ }^{35} \mathrm{~S}\right]$ methionine, and for the analysis of proteins by one- and two-dimensional gel electrophoresis are presented in the accompanying paper (Sweadner, 1983). S2 and S4 were released from the cells by treatment with $0.5 \mathrm{~mm} p$-chloromercuribenzene sulfonate (pCMBS) in minimal salts solution for 1 to $1.5 \mathrm{hr}$.

The Stokes radii of the labeled proteins were determined by chromatography on a column of Sepharose CL6B (Pharmacia, Piscataway, NJ), by comparing their elution positions with those of standard proteins of known dimensions. The column was $0.7 \times 27 \mathrm{~cm}$ and was operated at a flow rate of $1.5 \mathrm{ml} / \mathrm{hr}$ at $4^{\circ} \mathrm{C}$, in $50 \mathrm{~mm}$ Tris-Cl, $\mathrm{pH} 7.2$, with or without $0.5 \%$ Nonidet P-40 (NP40; Particle Data, Inc., Elmhurst, IL). Calibration proteins were aldolase $(48.1 \AA)$, catalase $(52.2 \AA)$, ferritin $(61.0 \AA)$, and thyroglobulin $(85.0 \AA)$, obtained as a gel filtration calibration kit from Pharmacia, and $E$. coli $\beta$ galactosidase $(67.0 \AA)$, obtained from Sigma Chemical Co. (St. Louis, MO). The fraction size was $250 \mu$ l, and the entire column was eluted in 50 fractions. The elution positions of the standard proteins were unchanged by the presence of the detergent NP-40. Cell extracts were prepared by incubating cells in $200 \mu \mathrm{l}$ of the column buffer (containing $0.5 \% \mathrm{NP}-40$ ) for $30 \mathrm{~min}$ on ice, and then sedimenting insoluble material by centrifugation at $140,000 \times g$ for $15 \mathrm{~min}$. Iodinated or $\left[{ }^{35} \mathrm{~S}\right]$ methioninelabeled cell extracts or aliquots of medium from pCMBStreated, labeled cells were chromatographed. Twentymicroliter samples of each column fraction were electrophoresed on one-dimensional gels, or 70- $\mu$ l samples were electrophoresed on two-dimensional gels. The position of the peak of each protein on the column was then determined from the autoradiograms of the gels.

Sedimentation coefficients were determined by comparison with the sedimentation of known standards by ultracentrifugation on sucrose gradients. Linear gradients from 5 to $20 \%$ sucrose in water, or from 5 to $15 \%$ sucrose in $\mathrm{D}_{2} \mathrm{O}$ (Sigma) (final concentration of $\mathrm{D}_{2} \mathrm{O}$, $94.8 \%$ ), were poured in 5-ml ultracentrifuge tubes. Gradients contained $0.5 \%$ NP-40. Samples $(200 \mu \mathrm{l}$ total) containing extracts of iodinated cells or aliquots of the medium of pCMBS-treated cells, together with the calibrating proteins $(100 \mu \mathrm{g}$ each), were loaded onto each gradient, and centrifugation was performed in a Beckman SW50 rotor at $48,000 \mathrm{rpm}$ for $5 \mathrm{hr}$. Fifty 3-drop fractions from each gradient were collected from a puncture in the bottom of the tube, and $20-\mu \mathrm{l}$ samples of each fraction were electrophoresed on gels. The position of the marker proteins was determined by staining the gels, whereas the labeled proteins were detected by autora- diography. The calibrating proteins were aldolase $\left(\mathrm{S}_{20, \mathrm{w}}\right.$ $7.0)$, catalase $\left(S_{20, w} 11.3\right), \beta$-galactosidase $\left(S_{20, w} 16.1\right)$, and thyroglobulin $\left(\mathrm{S}_{20, w} 19.2\right)$. The aldolase and $\beta$-galactosidase were obtained from Sigma, and the catalase and thyroglobulin were obtained from Pharmacia.

\section{Results and Calculations}

Hydrodynamic analysis. The Stokes radius of a protein can be determined by comparing its elution position on gel filtration columns with those of standard proteins of known dimensions (Siegel and Monty, 1966). The calibration of a column of Sepharose CL-6B with several globular proteins is shown in Figure 1. When iodinated cell surface proteins of sympathetic neurons, dissolved in the non-ionic detergent NP-40, were chromatographed in detergent, B1 eluted at the position expected for a globular protein of $M_{\mathrm{r}}=560,000$ or a radius of $76.5 \AA$ (Fig. 2A). There was no detectable B1, B2, B3, or B4 in the column void volume, indicating that solubilization was complete even under the gentle conditions used $\left(0.5 \% \mathrm{NP}-40\right.$ at $\left.0^{\circ} \mathrm{C}\right) . \mathrm{B} 1, \mathrm{~B} 2, \mathrm{~B} 3$, and $\mathrm{B} 4$ are not well resolved on one-dimensional gels, but their presence at the indicated positions was determined by analyzing each of the relevant fractions on a two-dimensional gel (data not shown; see the accompanying paper for representative two-dimensional gel patterns). Proteins released from iodinated neurons by treatment with pCMBS were chromatographed in the absence of detergent, and the largest of these (S2) eluted at the position of a globular protein of about $M_{\mathrm{r}}=530,000$, or $68.0 \AA$ (Fig. $2 B$ ). The data for the rest of the proteins are shown in Table I.

Given that the monomer molecular weights of these proteins are slightly over 200,000 by electrophoresis in

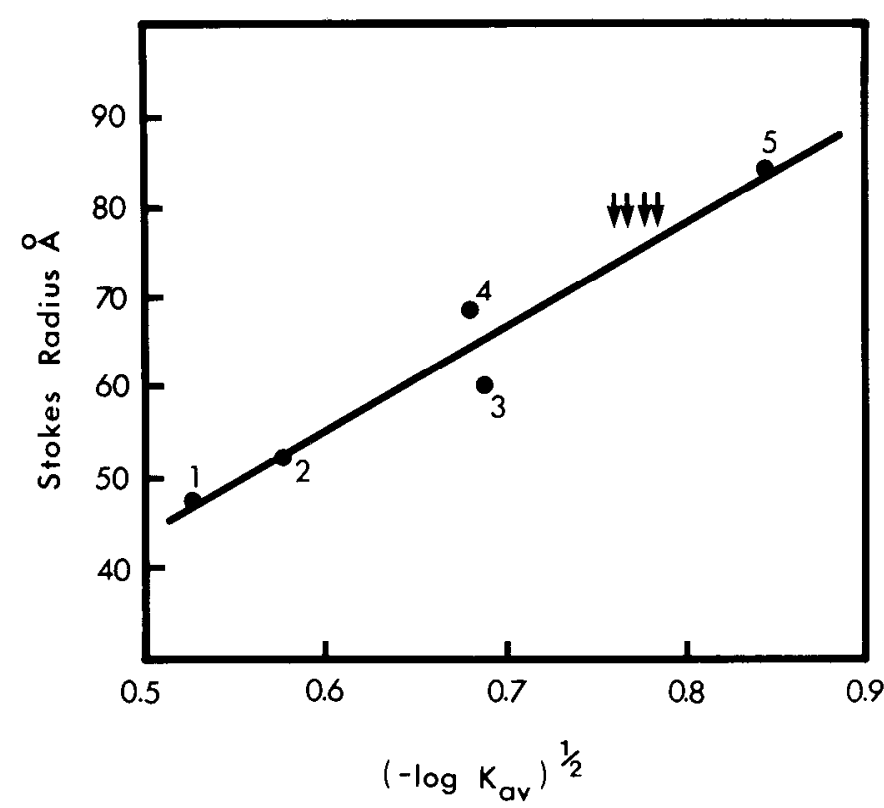

Figure 1. Calibration of the Sepharose CL-6B column. The Sepharose column was calibrated with (1) aldolase, (2) catalase, (3) ferritin, (4) E. coli $\beta$-galactosidase, and (5) thyroglobulin. $K_{\mathrm{av}}$ is the elution volume minus the void volume, divided by the total volume minus the void volume. The elution positions of (from left to right) B4, B3, B2, and B1 are marked with arrows. 


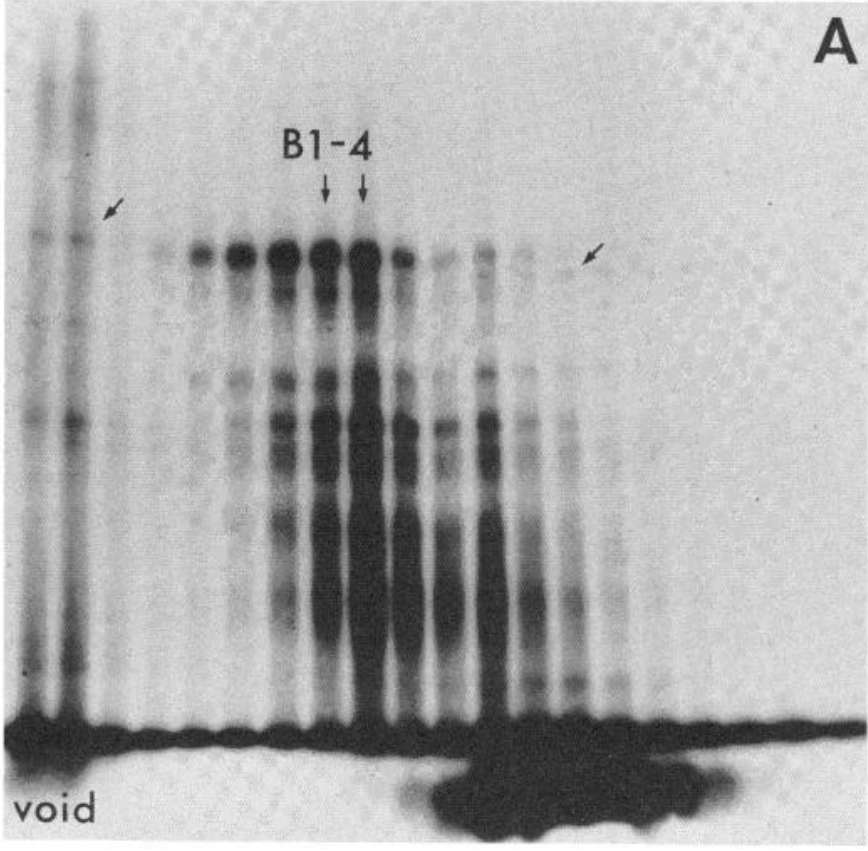

$$
\text { S } 2,4 \vec{\longrightarrow}
$$

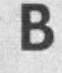

Figure 2. Sepharose chromatography of iodinated neuronal surface proteins. $A$, Neurons were labeled with ${ }^{125} \mathrm{I}$ and extracted with $0.5 \%$ NP-40 in $50 \mathrm{~mm}$ Tris- $\mathrm{Cl}, \mathrm{pH} 7.2$, and the extract was chromatographed on Sepharose CL-6B. Aliquots of each fraction were analyzed by electrophoresis on a one-dimensional gel of $6 \%$ acrylamide. Proteins B1, B2, B3, and B4 eluted at the positions indicated with arrows. Proteins B2 and B4 are not resolved on the one-dimensional gel, but their presence and elution positions were confirmed by resolving each of the six fractions closest to the peak of $\mathrm{B} 1$ and $\mathrm{B} 3$ on two-dimensional gels. The same result was obtained when $\left[{ }^{35} \mathrm{~S}\right]$ methioninelabeled neurons were chromatographed. The other two arrows mark the position of two unrelated, collagen- or mediumderived proteins which have similar apparent molecular weights by gel electrophoresis, but very different hydrodynamic properties. Iodinated lipids are seen as the large spot electrophoresing in front of the tracking dye, several fractions after the elution of B1 to B4. B, Proteins S2 and S4 and lower molecular weight components were released from iodinated cultures by treatment with pCMBS and chromatographed in the absence of detergent. Nothing eluted in the void volume of the column. Released proteins were also chromatographed in the presence of detergent, without any effect on their elution positions (not shown).

sodium dodecyl sulfate (SDS), there are two possible explanations for their behavior on Sepharose: $(i)$ the proteins elute as dimers or multimers of several subunits, or (ii) the proteins are highly asymmetric or highly hydrated. A rod-shaped or basket-like protein of given molecular weight will have a much larger Stokes radius than a compact sphere, causing an overestimation of its molecular weight by gel filtration (Nozaki et al., 1976). The two possibilities can be distinguished by determining the sedimentation coefficient. The molecular weight can be calculated from the Stokes radius and the sedimentation coefficient (Siegel and Monty, 1966):

$$
M=6 \pi \eta N a s /(1-\tilde{v} \rho)
$$

which is approximately

$$
M=4.192 \times 10^{23}(a)\left(S_{20, \mathrm{w}}\right)
$$

when the partial specific volume, $\bar{v}$, is taken to be 0.73 $\mathrm{gm} / \mathrm{cm}^{3}$, when viscosity, $\eta$, is taken to be $0.01002 \mathrm{gm} /$ $\mathrm{cm} \cdot \mathrm{sec}$, and the density of the medium, $\rho$, is taken to be $0.9982 \mathrm{gm} / \mathrm{cm}^{2} . N$ is Avogadro's number, $a$ is the Stokes radius expressed in centimeters, and $\mathrm{S}_{20, \mathrm{w}}$ is the sedimentation coefficient at $20^{\circ} \mathrm{C}$ in water, expressed in seconds $\times 10^{-13}$. From this, one would predict that a globular protein of $M_{\mathrm{r}}=560,000$ with Stokes radius of $76.5 \AA$ would have an $\mathrm{S}_{20, \mathrm{w}}$ value of about 17.5.

The sedimentation coefficient can be determined by centrifugation on sucrose gradients, since the rate at which a protein moves in a linear sucrose density gradient is approximately constant and independent of angular acceleration (Martin and Ames, 1961). Gradients were calibrated with thyroglobulin $\left(\mathrm{S}_{20, \mathrm{w}} 19.2\right), \beta$-galactosidase (16.1), catalase (11.3), and aldolase (7.0), as described under "Materials and Methods." A straight line was obtained when $S_{20, w}$ was plotted against distance migrated (Fig. 3), and the $\mathrm{S}_{20, \mathrm{w}}$ for protein $\mathrm{B} 1$ (Fig. $4 A$ ) was determined by extrapolation of the line to be only 5.0. The $\mathrm{S}_{20, \mathrm{w}}$ of protein $\mathrm{S} 2$ by the same procedure was 5.6 (Fig. $4 B$ ). From these values, a molecular weight of $\sim 163,550$ is obtained for $\mathrm{B} 1$, and of 159,600 for $\mathrm{S} 2$, using equation 1.

Since B1, B2, B3, and B4 are glycoproteins solubilized in detergent, their actual partial specific volumes might be different from the assumed value of 0.73 . Heavily glycosylated proteins have lower partial specific volumes ( 0.58 to 0.68 ) because carbohydrate is denser than protein. NP-40 has a partial specific volume of 0.943 (data from the supplier), and a protein which binds substantial amounts of detergent or lipid will have a higher partial specific volume (0.78 to 0.84 ) (Helenius and Simons, 1972; Clarke, 1975). The partial specific volume can be measured by comparing the sedimentation coefficients obtained in sucrose gradients made with $\mathrm{H}_{2} \mathrm{O}$ and $\mathrm{D}_{2} \mathrm{O}$ (Edelstein and Schachman, 1967; Meunier et al., 1972; Neer, 1974; Clarke, 1975). The calibration of $\mathrm{D}_{2} \mathrm{O}$ sucrose

\section{TABLE I}

Hydrodynamic parameters

Hydrodynamic parameters were obtained from the analysis of gel filtration chromatography and sedimentation velocity. Molecular weights and frictional coefficients were calculated assuming a partial specific volume of $0.73 . S_{20, D}$ is actually the $S_{20, w}$ as determined in $\mathrm{D}_{2} 0$ gradients.

\begin{tabular}{ccllccc}
\hline Protein & $\begin{array}{c}\text { Stokes } \\
\text { Radius }\end{array}$ & $\mathrm{S}_{20, \mathrm{w}}$ & $\mathrm{S}_{20, \mathrm{D}}$ & $\begin{array}{c}M_{\mathrm{r}} \\
\text { by eq. 1 }\end{array}$ & $\begin{array}{c}M_{\mathrm{r}} \\
\text { by Gel }\end{array}$ & $f / f_{\mathrm{o}}$ \\
\hline $\mathrm{B} 1$ & 76.5 & 5.0 & 5.2 & 163,550 & 230,000 & 2.12 \\
$\mathrm{~B} 2$ & 75.6 & 4.7 & 5.0 & 153,700 & 215,000 & 2.13 \\
$\mathrm{~B} 3$ & 74.3 & 4.4 & 4.7 & 141,700 & 200,000 & 2.15 \\
$\mathrm{~B} 4$ & 73.7 & 4.2 & 4.5 & 134,400 & 185,000 & 2.18 \\
$\mathrm{~S} 2$ & 68.0 & 5.55 & 5.65 & 159,600 & 215,000 & 1.89 \\
$\mathrm{~S} 4$ & 68.0 & 5.05 & 4.90 & 141,800 & 185,000 & 1.97 \\
\hline
\end{tabular}




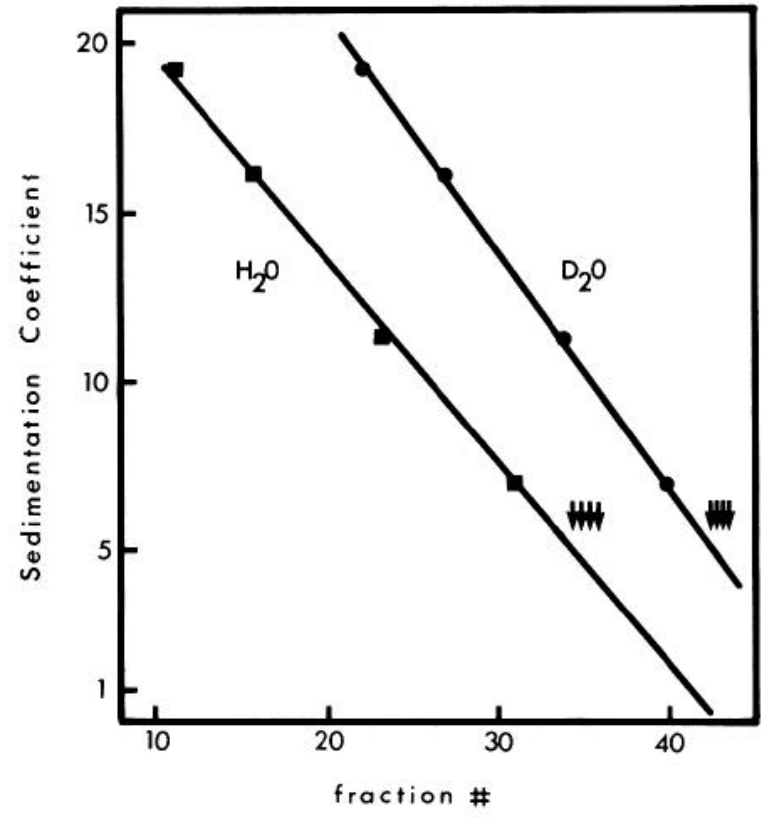

Figure 3. Calibration of the $\mathrm{H}_{2} \mathrm{O}$ and $\mathrm{D}_{2} \mathrm{O}$ sucrose gradients. The position of the marker proteins thyroglobulin, $\beta$-galactosidase, catalase, and aldolase is shown from left to right on both $\mathrm{H}_{2} \mathrm{O}$ - and $\mathrm{D}_{2} \mathrm{O}$-containing sucrose gradients. Proteins $\mathrm{B} 1$ to B4 sedimented to a position above aldolase in both gradients, as marked with arrows. The slope of the lines for $\mathrm{H}_{2} \mathrm{O}$ and $\mathrm{D}_{2} \mathrm{O}$ are actually different (Meunier et al., 1972); they appear to be similar here, but the $\mathrm{H}_{2} \mathrm{O}$ gradient is of 5 to $20 \%$ sucrose, whereas the $\mathrm{D}_{2} \mathrm{O}$ gradient is of only 5 to $15 \%$ sucrose.

gradients gives a line of a different slope (Fig. 3). For the proteins $\mathrm{B} 1, \mathrm{~B} 2, \mathrm{~B} 3$, and $\mathrm{B} 4$, and $\mathrm{S} 2$ and $\mathrm{S} 4$, the sedimentation coefficients relative to the standard proteins were the same in $\mathrm{H}_{2} \mathrm{O}$ and $\mathrm{D}_{2} \mathrm{O}$ within the error of the measurements ( \pm one fraction). It was concluded that the net partial specific volume of the sedimenting particles is approximately that of the marker proteins, 0.73 . Detergent binding of less than $10 \%$ of the weight of the protein (equivalent to a partial specific volume of 0.75 ) would be below the level of detection in the present experiments. The observed value may be due to the presence of only small amounts of carbohydrate or detergent, or to the presence of larger amounts of both carbohydrate and detergent that make equivalent contributions to partial specific volume. It is likely that B1, $\mathrm{B} 2, \mathrm{~B} 3$, and B4 bind some detergent, since they are not released from the membrane in its absence, and it is known that they contain some carbohydrate. A similar result has been reported for another membrane glycoprotein, the acetylcholine receptor (Meunier et al., 1972).

With the measured values of Stokes radius, sedimentation coefficient, and partial specific volume, and the calculated molecular weight, one can calculate the frictional ratio, $f / f_{o}$, to determine whether the protein is compact and globular (Siegel and Monty, 1966):

$$
f / f_{o}=a[4 \pi N / 3 M(\bar{v})]^{1 / 3}
$$

where $f / f_{o}$ is the calculated frictional coefficient divided by the frictional coefficient of a sphere of the same volume. For protein $\mathrm{B} 1, f / f_{o}$ is 2.12 . For a soluble protein this would indicate a highly asymmetric shape or an exceptional level of hydration. For comparison, $f / f_{o}$ for fibrinogen is 2.34, for myosin, 3.53, and for collagen, 6.8 (Tanford, 1961). The hydrodynamic parameters for all of the proteins are presented in Table I.

Analysis of detergent micelle size. One can calculate that the observed hydrodynamic properties are not likely to be the result of the association of the proteins with whole detergent micelles, which is known to occur for some membrane proteins (Osborne et al., 1974; Robinson and Tanford, 1975). A measurement of the Stokes radius
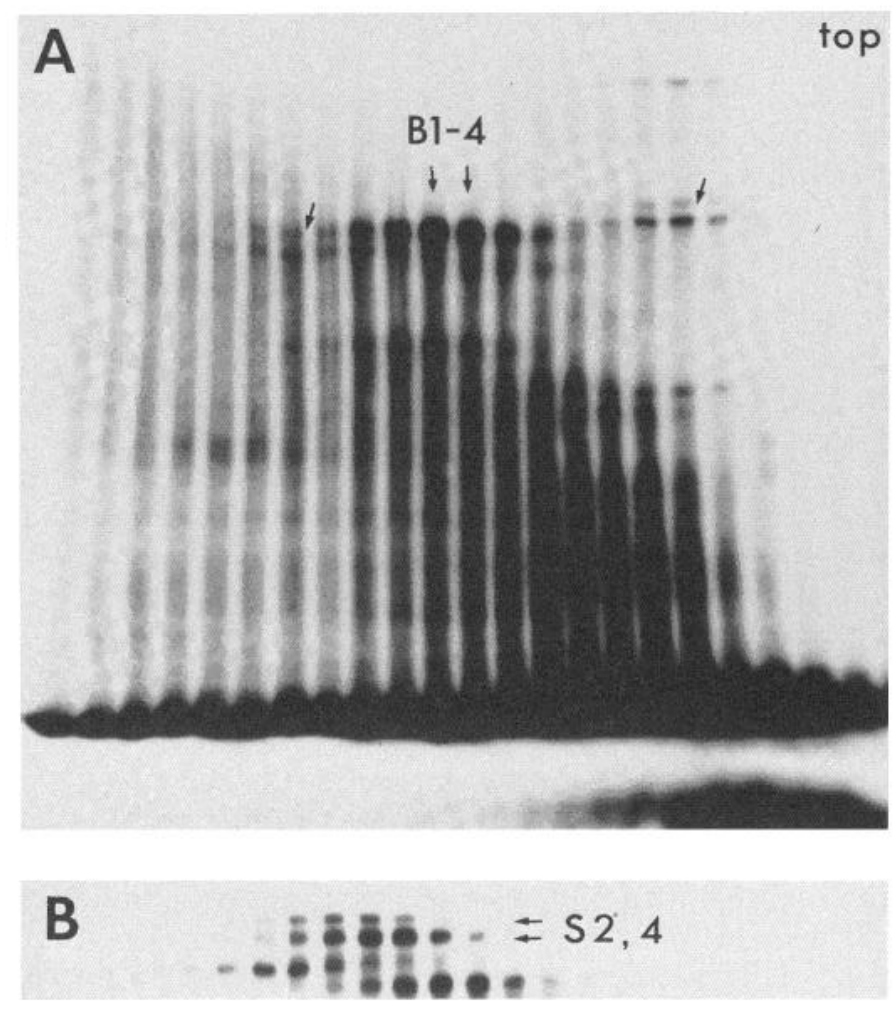

Figure 4. Sedimentation velocity analysis of iodinated neuronal surface proteins. $A$, Extracts of iodinated neuronal surface proteins were prepared as in Figure 2 and were sedimented with unlabeled marker proteins on sucrose gradients in $\mathrm{H}_{2} \mathrm{O}$ and $\mathrm{D}_{2} \mathrm{O}$, with $0.5 \% \mathrm{NP}-40$. Aliquots of each gradient fraction were electrophoresed on one-dimensional gels of $6 \%$ acrylamide. Because of the large number of fractions, two gels with 24 samples each were required for each gradient. The gels were stained to detect the positions of the marker proteins, and then autoradiographed to detect the neuronal proteins. The autoradiogram of the gel containing the top half of the $\mathrm{H}_{2} \mathrm{O}$ gradient is shown. The positions of proteins B1 to B4 and of the two unrelated proteins seen in Figure 2 are marked with arrows. The presence of $\mathrm{B} 2$ and $\mathrm{B} 4$ at the indicated positions was confirmed by electrophoresing those fractions on two-dimensional gels. Also as in Figure 2, the iodinated lipid in detergent micelles is seen migrating before the tracking dye, close to the top of the gradient. $B$, Iodinated released proteins were prepared as in Figure $2 B$ and were chromatographed on sucrose gradients. The autoradiogram of the gel of the top half of the $\mathrm{H}_{2} \mathrm{O}$ gradient is shown. $\mathrm{S} 2$ and $\mathrm{S} 4$ are marked with arrows. The heavily labeled, faster-sedimenting protein that migrates below S4 may be one of the minor released components; if so, it behaves as a more symmetrical particle than $\mathrm{S} 2$ or $\mathrm{S} 4$. No data are available about the relationship of the lower molecular weight released components to $\mathrm{S} 2$ and $\mathrm{S} 4$. 
and sedimentation coefficient of mixed micelles (NP-40 and lipid derived from the cultures) was made by using the position of iodinated lipid as a micelle marker on both the gel filtration column and the sucrose gradients. This gives an upper estimate of the size of a micelle of pure detergent, since lipid is thought to increase the size of micelles of the similar detergent Triton X-100 by as much as $50 \%$ (Yedgar et al., 1974). The iodinated lipids were detected as the label which electrophoreses before the tracking dye on the SDS gels (Figs. $2 A$ and $4 A$ ). The Stokes radius obtained was $50.1 \AA$, while the sedimentation coefficient was estimated to be 1.2 by extrapolation from the standards. This gives a molecular weight for the micelle of 116,500 from equation 1 . The average molecular weight for NP-40 molecules is 600 (data from the supplier); thus there are approximately 200 molecules per micelle. This is somewhat larger, but similar to values obtained for other non-ionic detergents (Yedgar et al., 1974; Tanford et al., 1977; Robson and Dennis, 1977). Equation 2 was used to calculate $f / f_{o}$ for the micelles, and a value of 1.43 was obtained; such micelles are thought to be oblate ellipsoids (Robson and Dennis, 1977; Tanford et al., 1977). If protein B1 were associated with one intact micelle, its net molecular weight could be only $\sim 50,000$. 'The partial specific volume of the particle would be approximately 0.85 to 0.9 , much higher than the observed value, even if the glycoprotein were composed of more than $50 \%$ carbohydrate.

Contrast with other proteins. For comparison with B1, B2, B3, B4, and S2 and S4, two unrelated sets of iodinated proteins can be seen in Figures $2 A$ and $4 A$ (angled arrows) that have similar apparent molecular weights, but very different hydrodynamic properties. Neither of these other sets of proteins is seen on gels of metabolically labeled neuronal proteins, which suggests that they are derived from the collagen substratum or the serumcontaining medium. One doublet has an apparent molecular weight of about 250,000 . It elutes in the void volume of Sepharose CL-6B and has a sedimentation coefficient of approximately 1.0 . Since even IgM (130 $\AA$ ) elutes after the void volume on this column, I have estimated the Stokes radius of the unknown protein to be $200 \AA$. This gives a molecular weight of $\sim 90,000$ and a $f / f_{o}$ of approximately 6.9 , which are the properties one would expect of a fibrous and rigid protein like a monomer of collagen. The other set of unknown proteins has a prominent band at 220,000 on the SDS gel and has a Stokes radius of $52.8 \AA$ and a sedimentation coefficient of 7.8 . These values give a molecular weight of $\sim 173,000$, and a $f / f_{o}$ of 1.43 , which is average for a large protein. The NILErelated proteins $\mathrm{B} 1, \mathrm{~B} 2, \mathrm{~B} 3$, and $\mathrm{B} 4$ lie between these two extremes.

\section{Discussion}

The molecular weights for B1, B2, B3, B4, S2 and S4 obtained from the hydrodynamic analysis are 25 to $30 \%$ lower than the molecular weights determined by electrophoresis in SDS. Since the molecular weights of sialic acid-containing glycoproteins are generally overestimated by electrophoresis in SDS (Segrest and Jackson, 1972), it is likely that the proteins are monomers and that the calculated molecular weights are very close to the true values. All of the proteins have large Stokes radii and small sedimentation coefficients, indicating that they have large frictional ratios. The simplest interpretation of the data is that they are shaped like elongated rods, which increases their effective size by gel filtration chromatography and decreases their sedimentation rate. Mathematically, a frictional ratio of 2.0 is equivalent to an axial ratio of about 20 for a prolate ellipsoid (Van Holde, 1971), but without a knowledge of hydration and complementary measurements of factors such as intrinsic viscosity one cannot make such a concrete prediction.

It is striking that the majority of the detergent-solubilized, lactoperoxidase-labeled proteins shown in Figures $2 A$ and $4 A$ have relatively high Stokes radii and low sedimentation coefficients. This behavior may prove to be a common, although not universal (Reynolds and Stoeckenius, 1977), characteritic of membrane proteins. Large soluble proteins typically have frictional ratios $\left(f / f_{o}\right)$ of 1.3 to 1.4 (Felgenhauer, 1974), but high values (1.6 to 1.7) have been obtained for a number of membrane proteins in Triton X-100 (Clarke, 1975), even proteins which would be expected to be more globular, such as opsin and the Na,K-ATPase. At this point there is discussion as to whether membrane proteins are usually asymmetric, or whether the apparent asymmetry is due to artifacts of detergent binding and hydration. The accuracy of the hydrodynamic measurements for B1, B2, B3, and B4 must be qualified by some uncertainties, but one can calculate that the limits of the uncertainties are not likely to permit the interpretation of the results as a detergent artifact. To explain the disparity between the large Stokes radius and small sedimentation coefficient by anything other than a rod-shaped or basket-like, highly hydrated protein, it would be necessary to invoke a large amount of detergent binding and considerable hydration of the detergent. Water molecules may in fact order themselves around the hydrophobic tails of detergent molecules, causing an overestimation of Stokes radius (Yedgar et al., 1974; Clarke, 1975), and the substitution of $\mathrm{D}_{2} \mathrm{O}$ for $\mathrm{H}_{2} \mathrm{O}$ should complicte the measurement of partial specific volume. In addition, detergent binding to membrane proteins in $\mathrm{D}_{2} \mathrm{O}$ can be as much as $20 \%$ lower than in $\mathrm{H}_{2} \mathrm{O}$ (Simons et al., 1973; Clarke, 1975), which would result in an erroneously low estimation of partial specific volume. An upper estimate for the influence of these factors on the hydrodynamic properties can be made by calculating $f / f_{0}$ with the highest possible value for partial specific volume: using $0.90, f / f_{o}$ for B1 would be reduced only from 2.12 to 1.98 . If the proteins are rod shaped, the techniques used may actually underestimate their frictional ratios; rod-shaped molecules can be retarded on gel filtration columns because of steric interactions with the gel matrix, resulting in an erroneously low value for Stokes radius (Nozaki et al., 1976). A more rigorous assessment of these factors will be possible only when purified B1, B2, B3, and B4 or S2 and $\mathrm{S} 4$ are available, to determine Stokes radius, carbohydrate content, and detergent binding by more direct means.

A hypothetical model for the structure of proteins B1, $\mathrm{B} 2, \mathrm{~B} 3$, and B4 would be a rod-shaped molecule with a 
hydrophobic tail that anchors it to the membrane; S2 and S4 could be released in soluble form by proteolytic cleavage of the hydrophobic tail. The strongest evidence, in fact, that the asymmetry of B1, B2, B3, and B4 is not an artifact of detergent binding is that S2 and $\mathrm{S} 4$, which appear to contain 93 to $97 \%$ of the mass of B1, B2, B3, and B4, also behave as asymmetric particles, and they do not require detergent for their solubility. The available evidence, however, does not tell us unambiguously how $\mathrm{B} 2$ and $\mathrm{B} 4$ are related to $\mathrm{S} 2$ and $\mathrm{S} 4$. Although the two sets of proteins comigrate on two-dimensional gels, the hydrodynamic data suggest that $\mathrm{S} 2$ and $\mathrm{S} 4$ are slightly less asymmetric and slightly higher in molecular weight than B2 and B4. Uncertainties in the detergent binding and carbohydrate contents of the proteins, however, result in uncertainties in the true molecular weights and preclude a rigorous comparison at this time. It is clear, however, that when released into the medium following transmitter release, $\mathrm{S} 2$ and $\mathrm{S} 4$ are released as monomers, and not as aggregates or membrane fragments.

There are other high molecular weight neuronal glycoproteins (NS-4, BSP-2, N-CAM, and NILE) that apparently are released spontaneously into the medium (see Sweadner, 1983, for references). The released proteins have been examined by gel filtration in two cases: N-CAM (neural cell adhesion molecule) released from retinal cell cultures elutes at the position of a globular protein of $M_{\mathrm{r}}=400,000$ (Thiery et al., 1977), and BSP2 components released from cerebellar cell cultures elute at the position of globular proteins of $M_{\mathrm{r}}=500,000$ and 300,000 (Goridis et al., 1980). Whether the proteins are actually globular or not was not determined; it is possible that they are rod shaped. Some hydrodynamic properties of preparations of N-CAM purified from NP-40 extracts of embryonic chick brain were analyzed by Hoffman et al. (1982). They found that the N-CAM was soluble but aggregated in detergent-free solutions. It eluted from gel filtration columns as a complex of at least $M_{\mathrm{r}}=1,000,000$, and it had an intrinsic viscosity comparable to that of a rod-like protein such as fibrinogen. Unfortunately, the data cannot be directly compared to the data on B1, B2, $\mathrm{B} 3$, and B4, because no detergent was used to keep the proteins solubilized. It will be of interest, however, to determine whether these superficially similar, high molecular weight glycoproteins are, in fact, all members of a family of related molecules.

\section{References}

Braun, S. J., K. J. Sweadner, and P. H. Patterson (1981) Neuronal cell surfaces: Distinctive glycoproteins of cultured adrenergic and cholinergic sympathetic neurons. J. Neurosci. 1: 1397-1406.

Clarke, S. (1975) The size and detergent binding of membrane protcins. J. Biol. Chem. 250: 5459-5469.

Edelstein, S. J., and H. K. Schachman (1967) The simultaneous determination of partial specific volumes and molecular weights with microgram quantities. J. Biol. Chem. 242: 306311.

Felgenhauer, K. (1974) Evaluation of molecular size by gel electrophoretic techniques. Hoppe-Seylers Z. Physiol. Chem. 355: 1281-1290.

Goridis, C., M. Hirsch, M. Dosetto, and E. Baechler (1980)
Identification and characterization of two surface glycoproteins on cultured cerebellar cells. Brain Res. 182: 397-414.

Helenius, A., and K. Simons (1972) The binding of detergents to lipophilic and hydrophilic proteins. J. Biol. Chem. 247: 3656-3661.

Hoffman, S., B. C. Sorkin, P. C. White, R. Brackenbury, R. Mailhammer, U. Rutishauser, B. A. Cunningham, and G. M. Edelman (1982) Chemical characterization of a neural cell adhesion molecule purified from embryonic brain membranes. J. Biol. Chem. 257: 7720-7729.

Lee, V. M., L. A. Greene, and M. L. Shelanski (1981) Identification of neural and adrenal medullary surface membrane glycoproteins recognized by antisera to cultured rat sympathetic neurons and PC12 pheochromocytoma cells. Neuroscience 6: 2773-2786.

Martin, R. G., and B. N. Ames (1961) A method for determining the sedimentation behavior of enzymes: Application to protein mixtures. J. Biol. Chem. 236: 1372-1379.

McGuire, J. C., L. A. Greene, and A. V. Furano (1978) NGF stimulates incorporation of fucose or glucosamine into an external glycoprotein in cultured rat $\mathrm{PC} 12$ pheochromocytoma cells. Cell 15: 357-365.

Meunier, J. C., R. W. Olsen, and J. P. Changeux (1972) Studies on the cholinergic receptor protein from Electrophorus electricus. Effect of detergents on some hydrodynamic properties of the receptor protein in solution. FEBS Lett. 24: 63-68.

Neer, E. J. (1974) The size of adenylate cyclase. J. Biol. Chem. 249: 6527-6531.

Nozaki, Y., N. M. Schechter, J. A. Reynolds, and C. Tanford (1976) Use of gel chromatography for the determination of the Stokes radii of proteins in the presence and absence of detergents. A reexamination. Biochemistry 15: 3884-3890.

Osborne, H. B., C. Sardet, and A. Helenius (1974) Bovine rhodopsin: Characterization of the complex formed with Triton X-100. Eur. J. Biochem. 44: 383-390.

Reynolds, J. A., and W. Stoeckenius (1977) Molecular weight of bacteriorhodopsin solubilized in Triton X-100. Proc. Natl. Acad. Sci. U. S. A. 74: 2803-2804.

Robinson, N. C., and C. Tanford (1975) The binding of deoxycholate, Triton X-100, sodium dodecyl sulfate, and phosphatidylcholine vesicles to cytochrome $b_{5}$. Biochemistry 14 : 369-378.

Robson, R. J., and E. A. Dennis (1977) The size, shape, and hydration of nonionic surfactant micelles. Triton X-100. J. Physical Chem. 81: 1075-1078.

Salton, S. R. J., C. Richter-Landsberg, L. A. Greene, and M. L. Shelanski (1983) Nerve growth factor-inducible large external (NILE) glycoprotein: Studies of a central and peripheral neuronal marker. J. Neurosci. 3: 441-454.

Schubert, D., and M. LaCorbiere (1982) The specificity of extracellular glycoprotein complexes in mediating cellular adhesion. J. Neurosci. 2: 82-89.

Segrest, J. B., and R. L. Jackson (1972) Molecular weight determination of glycoproteins by polyacrylamide gel electrophoresis in sodium dodecyl sulfate. Methods Enzymol. 28B: 54-63.

Siegel, L. M., and K. J. Monty (1966) Determination of molecular weights and frictional ratios of proteins in impure systems by use of gel filtration and density gradient centrifugation. Application to crude preparations of sulfite and hydroxylamine reductases. Biochim. Biophys. Acta 112: $346-$ 362.

Simons, K., A. Helenius, and H. Garoff (1973) Solubilization of the membrane proteins from Semliki Forest Virus with Triton X-100. J. Mol. Biol. 80: 119-133.

Sweadner, K. J. (1981) Environmentally regulated expression of soluble extracellular proteins of sympathetic neurons. J. Biol. Chem. 256: 4063-4070. 
Sweadner, K. J. (1983) Post-translational modification and evoked release of two large surface proteins of sympathetic neurons. J. Neurosci. 3: 2504-2517.

Tanford, C. (1961). Physical Chemistry of Macromolecules, John Wiley \& Sons, Inc., New York.

Tanford, C., Y. Nozaki, and M. F. Rohde (1977) Size and shape of globular micelles formed in aqueous solution by $\mathrm{n}$-alkyl polyoxyethylene ethers. J. Physical Chem. 81: 1555-1560.

Thiery, J. P., R. Brackenbury, U. Rutishauser, and G. M.
Edelman (1977) Adhesion among neural cells of the chick embryo. II. Purification and characterization of a cell adhesion molecule from neural retina. J. Biol. Chem. 252: 68416845.

Van Holde, K. E. (1971) Physical Biochemistry, Prentiss-Hall, Englewood Cliffs, NJ.

Yedgar, S., Y. Barenholz, and V. G. Cooper (1974) Molecular weight, shape and structure of mixed micelles of Triton $\mathrm{X}$ 100 and sphingomyelin. Biochim. Biophys. Acta 363: 98-111. 